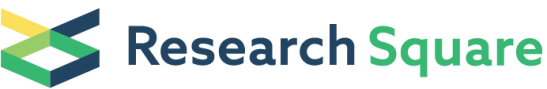 \\ Preprints are preliminary reports that have not undergone peer review. \\ They should not be considered conclusive, used to inform clinical practice, or referenced by the media as validated information.
}

\section{Cognitive Leisure Activity and All-cause Mortality in Older Adults: A 4-Year Community-based Cohort}

Qianyi Xiao ( $\nabla$ xiaoqianyi@fudan.edu.cn )

Fudan University

Xin Liu

Fudan University

Ye Ruan

Shanghai Municipal Center for Disease Control and Prevention

Limei Huang

songjiang center of disease prevention and control

Yanfei Guo

songjiang center of disease prevention and control

Shuangyuan Sun

songjiang center of disease prevention and control

Hao Chen

Fudan University

Junling Gao

Fudan University

Yan Shi

Shanghai Municipal Center for Disease Control and Prevention

\section{Research article}

Keywords: Cognitive leisure activity, mortality, older adults, cohort study

Posted Date: January 18th, 2021

DOl: https://doi.org/10.21203/rs.3.rs-42686/v2

License: (c) (i) This work is licensed under a Creative Commons Attribution 4.0 International License.

Read Full License

Version of Record: A version of this preprint was published at BMC Geriatrics on April 9th, 2021. See the published version at https://doi.org/10.1186/s12877-021-02180-3. 


\section{Abstract}

Background: Cognitive leisure activity, such as reading, playing mahjong or cards and computer use, is common among older adults in China. Previous studies suggest a protective role of cognitive leisure activity against cognitive impairment. However, the relationship between cognitive leisure activity and allcause mortality has rarely been reported.

Objectives: This study aims to explore the relationships between cognitive leisure activity and all-cause mortality in a community-based elderly cohort in China.

Methods: The current study sample comprised 4003 community residents aged $\geq 60$ y who were enrolled in June 2015, and were followed up every year from 2015 to 2018. Reading, playing mahjong or cards and computer use were measured by questionnaires and summed into a cognitive leisure activity index (CLAI) score. Cox proportional hazards analysis and Kaplan-Meier survival analysis were used to examine the association of cognitive leisure activity with all-cause mortality.

Results: During the 4-year follow-up of 4003 participants, 208 (5.2\%) deaths were registered. Of all participants, $66.8 \%, 26.7 \%, 6.1 \%$ and $0.35 \%$ reported CLAl scores of $0,1,2$ and 3 , respectively. A strong association was noted between the CLA score and all-cause mortality (adjusted hazard ratio $[\mathrm{HR}]=0.72$, $95 \%$ confidence intervals [CI]: 0.54-0.96, $P=0.025)$. Stratified analysis suggested that a higher CLAl score was significantly associated with a decreased risk of all-cause mortality mainly among those who were male, aged $\geq 80 \mathrm{y}$, cognitively impaired, and not diagnosed with cancer $(P<0.05)$.

Conclusion: Cognitive leisure activity has beneficial effect on reduced risk of death from all cause among the elderly in China, which helped promote a comprehensive understanding of health characteristics at advanced ages.

\section{Background}

The elderly population has been increasing worldwide, presenting a major challenge to the health and social care system. Chronic diseases are the leading causes of death and disability worldwide ${ }^{1}$. Many studies have implicated lifestyle risk behaviour, such as smoking ${ }^{2}$, alcohol use ${ }^{3}$ and physical inactivity ${ }^{4}$, in adverse health outcomes, including cardiovascular disease, dementia, diabetes, some cancers, and mortality ${ }^{5}$. Hence, substantial disease, mortality, and economic burden could be prevented through modification of lifestyle behaviours ${ }^{6-8}$.

Cognitive leisure activity, such as computer use, reading and playing mahjong or cards ${ }^{9-11}$, is a type of modifiable lifestyle behaviour and popular in old adults especially retired people in China. In the past few years, the beneficial effect of cognitive leisure activity on cognitive function has been reported. For example, computer use has been reported to improve cognitive function in older people ${ }^{12}$. Several studies have also identified that reading $9-11,13,14$, playing board games (mahjong, chess or poker) ${ }^{15,16}$, and 
playing cards ${ }^{11,17}$ were associated with a reduced risk of cognitive impairment. It is noteworthy that dementia is one of the most common cognitive-related disorders, ranking as the sixth leading cause of death in the United States and the fifth leading cause of death in Americans aged $\geq 65$ years $^{18}$. It is projected that, by $2050,1.6$ million or $43 \%$ of older adult deaths will be due to dementia and Alzheimer's disease ${ }^{19}$. In addition, accumulating evidence has indicated that leisure activity, including watching TV20, internet use ${ }^{21}$ and reading 22,23 , can make a significant contribution to overall life satisfaction ${ }^{24-26}$, which has been identified as an important risk factor for mortality in older people ${ }^{27-29}$. Recently, a prospective cohort study indicated that playing cards or mahjong and reading were association with lower all-cause mortality in the Chinese oldest-old population ${ }^{30}$. Another study found an association between daily book reading and survival among men but not women ${ }^{31}$. All these studies compel us to examine whether cognitive leisure activity is associated with all-cause mortality, which has rarely been reported.

Using a 4-year prospective cohort study, the present study explores a range of cognitive leisure activities, including reading, playing mahjong or cards, and computer use. The objective of this study was to examine the association between cognitive leisure activity and all-cause mortality.

\section{Methods}

\section{Sampling and procedures}

The analyses are based on data from the community physical examination project for the elderly in Songjiang District, Shanghai, and the purpose of the original study is to exploring the community prevention and intervention of key diseases in the elderly. We recruited a random sample of 4050 participants, representative of the noninstitutionalized population aged $\geq 60$ years in Songjiang District, Shanghai, China. Baseline data collection was conducted from June 2015 to March 2016. At baseline, demographic and characteristic data, including birth date, gender, height, weight, education years, lifestyles, physical activity (PA), cognitive leisure activity (reading, playing mahjong or cards and computer use), Dementia Screening Interview (AD8) score, medical histories of diabetes, hypertension, coronary heart disease (CHD) and stroke (classified as yes or no), were collected via a face-to-face questionnaire survey by trained personnel. Participants joined the study by completing the questionnaire and the written informed consent form.

\section{Measures}

Mortality. All-cause mortality and the date of death were ascertained from the Death Surveillance System of Songjiang CDC for all participants after each follow-up, from July 29, 2016 to October 31, 2018. Research coordinators contacted all the participants based on their contact information recorded at the baseline survey and asked for the availability of a clinical interview. Individuals who were deceased were recorded. The date of death was provided by their family members via the telephone call and confirmed by the Death Surveillance System of Songjiang CDC. Those who could not be traced or refused to 
participate were defined as "lost to follow-up". Participants who missed any of three data points of reading, playing mahjong or cards and computer use at baseline were excluded.

Cognitive leisure activity index construction. Participants reported on a range of cognitive leisure activities in the questionnaire. Reading status was derived from the question "Do you read books or newspapers every day?" Here, "hardly reading" was defined as having no reading habits, whereas "occasionally reading" and "daily reading" were defined as having reading habits. Participants were asked, "Do you often play cards or mahjong?" Among the responses, "almost do not play " was defined as having no habit of playing cards or mahjong, and "several times a month" and "several times a week" were defined as having the habit of playing cards or mahjong. A similar question was also asked, "Do you often use computers to access the internet?" With "Not at all" defined as having no Internet habits, whereas "not every day" and "every day (more than an hour at a time)"were defined as having internet habits.

Considering the beneficial role of these three cognitive leisure activities in cognitive impairment ${ }^{12,13,15-17}$, 32-35 and mortality ${ }^{30,31}$, and the trend of beneficial effect on reduced mortality risk in our study (supplementary Figure 1), each cognitive leisure activity was coded as 1 (beneficial) or 0 (not beneficial) and summed as cognitive leisure activity index (CLAl) (total score ranging from 0 to 3 ).

Covariates. Sociodemographic characteristics were collected from participants' self-reports or physical examinations. Age, sex, BMI (underweight, normal, overweight and obese), education (illiterate, primary school and $\geq$ junior school), marital status (married and single), and work status (retired, still working, no work) were assessed. BMI was calculated as weight in kilograms divided by height in metres squared. Based on the BMI classification guidelines of the World Health Organization revised for the Asia-Pacific region, we classified the $\mathrm{MCl}$ participants into underweight $\left(\mathrm{BMl}<18.5 \mathrm{~kg} / \mathrm{m}^{2}\right.$ ), normal (BMl: 18.5 22.9 $\mathrm{kg} / \mathrm{m}^{2}$ ), overweight (BMl: $23.0 \sim 29.9 \mathrm{~kg} / \mathrm{m}^{2}$ ) and obese $\left(B M I \geq 30.0 \mathrm{~kg} / \mathrm{m}^{2}\right)$ groups. Smoking status was categorized as current smokers, never smokers, and people who given up smoking. Drinking status was divided into drinking and never drinking. PA was assessed based on self-reports of leisure-time activities, such as fasting walking, playing balls, running, or qigong. (Average physical activity time must exceed 10 minutes per day.) Participants rated their PA levels as (1) inactive, (2) several times a month, (3) 3$4 \times /$ week, or (4) almost every day. Cognitive assessment were performed according to the AD8 screening questionnaire, participants with AD8 score ${ }^{3} 2$ were defined as probably cognitive impairment, whereas AD8 score $<2$ was defined as cognitive normal. In addition, we created a dichotomous variable for cardiovascular or metabolic disease based on the self-report of CHD, stroke, hypertension, and diabetes. Based on the sample distribution, the index of cardiovascular or metabolic disease (CHD, stroke, hypertension, diabetes) was categorized as 0 and 1 (at least one disease). We created an additional dichotomous variable for cancer based on self-report and medical record.

\section{Statistical Analysis}


All statistical analyses were performed using SPSS version 22.0 (SPSS, Chicago, IL, USA). Hazard ratios (HRs) and 95\% confidence intervals (Cls) were estimated using Cox proportional hazard models for the analysis of the association between CLAl and mortality. Kaplan-Meier curves were also used to estimate the relationship between CLAl and mortality. The outcome variable was survival time, which was measured as the time interval from the date of baseline data collection to death or censoring. All Cox proportional hazards regression models were adjusted for sex, age (continuous variable), BMI (continuous variable), educational attainment, marital status, work status, smoking status, drinking status, PA, cardiovascular disease, and cancer with covariates classified categorically as per Table 1 . We also examined the independent association of each cognitive leisure activity and all-cause mortality.

Table1םSocio-demographic and health characteristics of adults by cognitive leisure activity index score. 


\begin{tabular}{|c|c|c|c|c|c|c|}
\hline \multirow[t]{2}{*}{ Variable } & \multirow[t]{2}{*}{$\begin{array}{l}\text { Total } \\
n\end{array}$} & \multicolumn{4}{|c|}{$\begin{array}{l}\text { Cognitive leisure activity index score } \\
n \text { (Column percentage) }\end{array}$} & \multirow[t]{3}{*}{$P$} \\
\hline & & 0 & 1 & 2 & 3 & \\
\hline Total & 4003 & 2674 & 1070 & 245 & 14 & \\
\hline Sex & & & & & & $\square 0.001$ \\
\hline Male & 1746 & $818(30.6)$ & $708(66.2)$ & $209(85.3)$ & $11(78.6)$ & \\
\hline Female & 2257 & $1856(69.4)$ & $362(33.8)$ & $36(14.7)$ & $3(21.4)$ & \\
\hline Age & & & & & & 00.001 \\
\hline $60-70 y$ & 2498 & $1531(57.3)$ & $770(72.0)$ & $185(75.5)$ & $12(85.7)$ & \\
\hline $70-80$ & 1150 & $846(31.6)$ & $250(23.4)$ & $53(21.6)$ & $1(7.1)$ & \\
\hline$\geq 80 \mathrm{y}$ & 355 & 297(11.1) & $50(4.7)$ & $7(2.9)$ & $1(7.1)$ & \\
\hline BMI & & & & & & $\square 0.001$ \\
\hline underweight & 241 & $177(6.6)$ & $51(4.8)$ & $12(4.9)$ & $1(7.1)$ & \\
\hline normal & 1482 & 1034(38.7) & $363(33.9)$ & $82(33.5)$ & $3(21.4)$ & \\
\hline overweight & 2084 & $1329(49.7)$ & $606(56.6)$ & $140(57.1)$ & $9(64.3)$ & \\
\hline obesity & 196 & $134(5.0)$ & $50(4.7)$ & $11(4.5)$ & $1(7.1)$ & \\
\hline Marital status & & & & & & $\square 0.001$ \\
\hline Married & 3193 & $2030(75.9)$ & $925(86.5)$ & $225(91.8)$ & $13(92.9)$ & \\
\hline $\begin{array}{l}\text { Single/ divorced/ } \\
\text { separated/ widowed/ } \\
\text { spinsterhood }\end{array}$ & 810 & $644(24.1)$ & 145(13.6) & $20(8.2)$ & $1(7.1)$ & \\
\hline Educational attainment & & & & & & $\square 0.001$ \\
\hline Illiteracy & 2260 & $1851(69.2)$ & $384(35.9)$ & $24(9.8)$ & $1(7.1)$ & \\
\hline Primary school & 1181 & $673(25.2)$ & $412(38.5)$ & $94(38.4)$ & $2(14.3)$ & \\
\hline$\geq$ junior school & 562 & $150(5.6)$ & $274(25.6)$ & $127(51.8)$ & $11(78.6)$ & \\
\hline Work status & & & & & & 00.001 \\
\hline Retired & 2009 & $1262(47.2)$ & $588(55.0)$ & $148(60.4)$ & 11(78.6) & \\
\hline Still working & 627 & $408(15.3)$ & 167(15.6) & $50(20.4)$ & $2(14.3)$ & \\
\hline No work & 1367 & $1004(37.5)$ & $315(29.4)$ & $47(19.2)$ & $1(7.1)$ & \\
\hline Physical activity & & & & & & $\square 0.001$ \\
\hline Inactive & 885 & $617(23.1)$ & 221(20.7) & $44(18.0)$ & $3(21.4)$ & \\
\hline Several times a month & 117 & $67(2.5)$ & $41(3.8)$ & $8(3.3)$ & $1(7.1)$ & \\
\hline $3-4 \mathrm{x} /$ week & 807 & $574(21.5)$ & 188(17.6) & $43(17.6)$ & $2(14.3)$ & \\
\hline Almost every day & 2194 & $1416(53.0)$ & $620(57.9)$ & $150(61.2)$ & $8(57.1)$ & \\
\hline Smoking & & & & & & $\square 0.001$ \\
\hline Former & 491 & $237(8.9)$ & 195(18.2) & $57(23.3)$ & $2(14.3)$ & \\
\hline Current & 843 & $344(12.9)$ & $369(34.5)$ & $122(49.8)$ & $8(57.1)$ & \\
\hline Never & 2669 & 2093(78.3) & $506(47.3)$ & $66(27.0)$ & $4(28.6)$ & \\
\hline Alcohol use & & & & & & $\square 0.001$ \\
\hline Drinker & 751 & $312(11.7)$ & $328(30.7)$ & $103(42.0)$ & $8(57.1)$ & \\
\hline Never & 3252 & $2362(88.3)$ & 742(69.3) & $142(58.0)$ & $6(42.9)$ & \\
\hline $\begin{array}{l}\text { Cardiovascular or metab } \\
\text { disease }\end{array}$ & & & & & & 0.047 \\
\hline $\begin{array}{l}\text { Physician-diagnosed in } \\
\text { past }\end{array}$ & 2064 & $1345(50.3)$ & $590(55.1)$ & $123(50.2)$ & $6(42.9)$ & \\
\hline Undiagnosed in past & 1939 & $1329(49.7)$ & $480(44.9)$ & $122(49.8)$ & $8(57.1)$ & \\
\hline Cancer & & & & & & 0.860 \\
\hline $\begin{array}{l}\text { Physician-diagnosed in } \\
\text { past }\end{array}$ & 87 & $58(2.2)$ & $26(2.4)$ & $3(1.2)$ & $0(0)$ & \\
\hline Undiagnosed in past & 3916 & $2616(97.8)$ & $1044(97.6)$ & $242(98.8)$ & $14(100)$ & \\
\hline
\end{tabular}




$\begin{array}{llllll}\text { Impairment } & 250 & 214(8.0) & 35(3.3) & 1(0.4) & 0(0) \\ \text { Normal } & 3753 & 2460(92.0) & 1035(96.7) & 244(99.6) & 14(100)\end{array}$

Based on the model with the CLAl as the exposure variable, we tested potential effect modification and presented stratified analyses by age group, sex, BMl, educational attainment, PA, cognitive status, whether individuals were diagnosed with cardiovascular or metabolic disease, and whether individuals were diagnosed with cancer. In stratified analyses, PA was stratified into a binary variable to intelligibly explain the interaction of PA and cognitive leisure activity on all-cause mortality: physically inactive versus physically active (several times a month, $3-4 \times /$ week, and almost every day). BMI was divided into two groups, including overweight $\left(\mathrm{BMI} \geq 23.0 \mathrm{~kg} / \mathrm{m}^{2}\right)$ and nonoverweight $\left(\mathrm{BMl}<23.0 \mathrm{~kg} / \mathrm{m}^{2}\right)$ groups, due to the small sample size in the underweight and obesity groups.

\section{Results}

\section{Descriptive statistics}

Among 4050 participants at baseline, 15 respondents of the final study were lost to follow-up, and 32 participants were excluded due to missing CLAl data at baseline. The final sample for analyses included 4003 participants with a mean follow-up of 3.08 (SD 0.39) years, of whom 208 (5.2\%) died prior to October 31, 2018. Table 1 describes the characteristics and the distribution of the final analytical sample. At baseline, the mean age of the participants was $69.37 \pm 7.06$ years (range 60-96). The majority of the participants were female (56.4\%), overweight (52.1\%), married (79.8\%), illiterate (56.5\%), retired (50.2\%), physically active almost every day (54.8\%), never smokers (66.7\%), never drinkers (81.2\%), diagnosed with cardiovascular or metabolic disease (51.6\%), not diagnosed with cancer (97.8\%), and cognitively normal (93.8\%). In addition, we found a greater proportion of illiterate among women than that among men $(70.6 \%$ vs. $38.2 \%, P \otimes 0.001$, Table S2), and lower proportion of each cognitive leisure activity (Table S2) in women than that in men.

For cognitive leisure activity, $14.9 \%$ of study participants had reading habits, $23.0 \%$ of them played mahjong or cards, and $2.1 \%$ of participants used computers. Overall, $66.8 \%$ of participants reported no cognitive leisure activity (CLAl score $=0$ ), $26.7 \%$ had one cognitive leisure activity, and $6.1 \%$ and $0.35 \%$ had CLAl scores of 2 and 3, respectively. Higher CLAl scores were more prevalent among males, those aged 60-70 y, those who were married, those who had a junior school degree or higher, those who were retired, and those who were cognitively normal $(P \otimes 0.05$, Table 1$)$.

\section{Individual Cognitive Leisure Activity and All-cause Mortality}

When all three dichotomized individual cognitive leisure activities were entered in the model with all covariates, playing mahjong or cards exhibited independent associations with all-cause mortality $(P=$ 0.007 , supplementary Figure S1). Reading and computer use also displayed potential beneficial roles in all-cause mortality but with no significant association with all-cause mortality (supplementary Figure S1). 


\section{Cognitive leisure activity Index and All-cause Mortality}

Kaplan-Meier survival analysis showed that participants with higher CLAl scores had a significantly decreased risk of death $(P=0.043$, Figure 1$)$. Cox proportional hazards regression analyses also showed an inverse association between the CLAI scores and all-cause mortality $(\mathrm{HR}=0.72,95 \% \mathrm{Cl} 0.54-0.96, P=$ 0.025), adjusted for age, sex, BMI, educational attainment, marital status, work status, smoking status, alcohol use status, physical activity, cardiovascular disease, and cancer. (Figure 2). All-cause mortality HRs compared to individuals without cognitive leisure activity were $0.71(P=0.045)$ and $0.47(P=0.049)$ for those with 1 and 2 cognitive leisure activities in univariate analysis, respectively, whereas these significances were not found in multivariate analysis (Figure 2).

Stratified analyses suggested an inverse association between CLAl scores and all-cause mortality among participants who were aged $\geq 80$ y $(\mathrm{HR}=0.42,95 \% \mathrm{Cl} 0.20-0.86, P=0.018)$, those who were male $(\mathrm{HR}=$ $0.68,95 \% \mathrm{Cl} 0.49-0.93, P=0.017)$, those who had cognitive impairment $(\mathrm{HR}=0.08,95 \% \mathrm{Cl} 0.01-0.65, P=$ 0.018 ), and those without a cancer diagnosis ( $\mathrm{HR}=0.71,95 \% \mathrm{Cl} 0.53-0.96, P=0.024)$ (Figure 3). There was also some indication that CLAI scores were associated with all-cause mortality in participants with $\mathrm{PA}$ inactive (HR $=0.52, P=0.014$ in univariate analysis, $\mathrm{HR}=0.60, P=0.070$ in multivariate analysis), who were nonoverweight $(\mathrm{HR}=0.63, P=0.016$ in univariate analysis, $\mathrm{HR}=0.66, P=0.052$ in multivariate analysis) and participant diagnosed with cardiovascular or metabolic disease (HR $=0.67, P=0.025$ in univariate analysis, $\mathrm{HR}=0.69, P=0.054$ in multivariate analysis). Considering the influence of disease status on physical activity, we furtherly analyzed the distribution of cardiovascular or metabolic disease, cancer and BMI between participants with PA active and PA inactive, and found no significant different distribution (Table S3).

\section{Discussion}

This is the first study to our knowledge to investigate an CLAl incorporating reading, playing mahjong or cards and computer use in relation to all-cause mortality. We found that multiple cognitive leisure activities among older Chinese adults were associated with a decreased risk for all-cause mortality over 4 $y$ of follow-up. A clear association was noted between the number of cognitive leisure activities, as indicated by the CLAI score, and all-cause mortality.

In the stratified analysis, we identified a significant relationship between cognitive leisure activity and allcause mortality among people with cognitive impairment. Previous evidence indicates the effect of cognitive leisure activities on cognitive health. $\mathrm{Li}$ and colleagues indicated that reading and computer use were associated with a lower risk of mild cognitive impairment in a population-based study ${ }^{36}$. Lindstrom et al. found an inverse relationship between intellectual activities (reading, playing cards, playing a musical instrument, and letter writing) and Alzheimer's disease or other forms of dementia in a US-based population ${ }^{17}$. Verghese et al reported that cognitive leisure activities (reading, writing, doing crossword puzzles, playing board games or cards, and playing musical instruments) were associated with a reduced risk of dementia ${ }^{11}$. Despite the heterogeneous measures, risk classification, sample characteristics, and 
follow-up time of these studies, the association between cognitive leisure activities and cognitive health has been consistent, suggesting the generalizability of these findings. This beneficial role of cognitive leisure activities is further supported here based on its beneficial effect on risk of all-cause mortality in older people in our study. Cognitive impairment has a significant impact on mortality and disability of order population ${ }^{37}$. According to data from the Centers for Disease Control and Prevention (CDC), 121,404 people died from Alzheimer's disease in 2017, and the rate of death from Alzheimer's disease dramatically increased with age, especially after age $65^{18}$. Therefore, cognitive leisure activities potentially influence mortality through protecting cognitive impairment.

It is worth noting that among the three dichotomized individual cognitive leisure activities, playing mahjong or cards exhibited an independent association with all-cause mortality. Consist with our findings, two previous studies reported decreased all-cause mortality among older participants who played cards or mahjong ${ }^{30,38}$. One explanation may be that playing mahjong or cards incorporates social engagement. Social engagement, which is defined as the maintenance of many social connections and a high level of participation in social activities, prevents cognitive decline in older persons ${ }^{39-41}$. Additionally, social activities predominantly affect the immune system and influence inflammatory processes in the brain $^{42,43}$. All these results support our findings that playing mahjong or cards has a beneficial effect on reduced mortality risk.

We found a strong association between cognitive leisure activities and all-cause mortality among men not women. Similarly, a previous study also found an association between daily book reading and survival among men but not women. Our findings showed greater proportion of illiterate among women than that among men $(70.6 \%$ vs. $38.2 \%, P \otimes 0.001)$, and lower proportion of each cognitive leisure activity in women than that in men (Table S2). For reading which depended on knowledge and literature, men are 4.5 times more likely than women to engage in reading (Table S2). Therefore, the reason for association between cognitive leisure activities and all-cause mortality among men not women may be due to more proportion of illiterate in women than that in men, which lead to the lower proportion of cognitive leisure activities.

Stratified analysis indicated a potential relation between cognitive leisure activity and all-cause mortality among participants with physical inactivity in late life $(\mathrm{HR}=0.52, P=0.014$ in univariate analysis, $\mathrm{HR}=$ $0.60, P=0.070$ in multivariate analysis, Figure 3 ), indicating the supplemental role of cognitive leisure activity in healthy living, especially for older people who are unable to perform effective physical activity due to severe chronic disease. Physical activity is a pivotal lifestyle behaviour. Regular physical activity has been irrefutably identified as a protective factor for all-cause mortality ${ }^{44-46}$, and the benefit of physical activity was independent of the type of physical activity ${ }^{47}$. Here, our study revealed the consistent effect of cognitive leisure activity with PA on all-cause mortality in an older population. In addition, some studies have indicated that cognitive function and physical function influence each other in a feedback loop ${ }^{48,49}$. A protective effect of physical activity against cognitive impairment has been reported in many studies ${ }^{50-53}$, and the benefits of physical activity on cognitive function can be attributed 
to an ameliorated overall health condition ${ }^{54}$. Conversely, cognitive leisure activity is associated with enhanced memory, executive function, language, and cognitive skill ${ }^{55}$, which may influence the practice of regular physical activity. For example, execution functions, including volition, planning, purposive action, performance monitoring and inhibition ${ }^{56}$, may enable older individuals to consistently engage in physical activity to achieve long-term health benefits ${ }^{57}$.

We also found that the CLAl score was associated with lower all-cause mortality in participants without cancer but not in cancer patients. This results Cancer is a malignant disease in which cognitive leisure activity is not significantly associated with all-cause mortality, as expected. In fact, many studies have shown the beneficial effect of cognitive leisure activity or social activity on quality of life. Hence, we believe that whether the cognitive health of cancer patients is improved or the survival rate of noncancer patients is improved, cognitive leisure activity should be considered in older people's health. In addition, our results indicated a potential beneficial effect of CLAls on reduced mortality risk among participants who were diagnosed with cardiovascular or metabolic disease $(\mathrm{HR}=0.67, P=0.025$ in univariate analysis, $\mathrm{HR}=0.69, P=0.054$ in multivariate analysis, Figure 3$)$. Accumulating evidence has indicated that leisure activity, including watching TV 20 , internet use ${ }^{21}$ and reading 22,23 , can make a significant contribution to overall life satisfaction and psychological well-being 24,25 , which is subsequently associated with a lower risk of cardiovascular disease ${ }^{61,62}$. Thus, a potential pathway by which cognitive leisure activity influences all-cause mortality may be through reducing the risk of cardiovascular disease or reducing the effect of cardiovascular disease on mortality.

Limitations in the current study should be acknowledged. First, it is important to acknowledge that not all three cognitive leisure activities contribute to mortality similarly and that their combined effects may not be additive. However, given the short follow-up period and small sample size, we did not obtain a sufficient prevalence of specific combination patterns of cognitive leisure activities to analyze their associations with all-cause mortality (e.g., prevalence of combination of reading and computer use, combination of playing mahjong or cards and computer use, and combination of both cognitive leisure activities were $1.0 \%(n=41), 0.2 \%(n=9)$ and $0.4 \%(n=14)$, respectively). Second, time spent in each activity was not measured, which may modify the effect of cognitive leisure activity on mortality. Third, because this study is a secondary analysis of data, we only investigated three kinds of cognitive leisure activities, which was not representative of the cognitive leisure activities of the elderly in China. Future study included comprehensive cognitive leisure activities need to performed to confirm the beneficial role of cognitive leisure activity in reducing the risk of mortality. Fourth, reading and computer use require literacy, whereas $56.5 \%$ of participants in our study was illiterate, which may lead to a lack of applicability of the study results in illiterate populations. Fifth, this study could be further strengthened by including cause-specific mortality outcomes, but these data are not yet available for the time period studied. Finally, this study assessed older Chinese adults living in a large city, Shanghai, thus potentially limiting the generalizability of our results.

\section{Conclusion}


This study demonstrates the importance of cognitive leisure activity in health lifestyle, here evidenced for adults aged $60 \mathrm{y}$ and older. This analysis investigated three cognitive leisure activities, namely, reading, playing mahjong or cards and using computers, which may be added to behavioural indices or risk combinations to quantify the health risk of older people in China. In addition, our findings advance current knowledge of older people's health and provide a new prevention strategy in older populations.

\section{Abbreviations}

PA: Physical Activity

CLAl: Cognitive Leisure Activity Index

HR: Hazard Ratio

Cl: Confidence Intervals

BMl: Body Mass Index

SPSS: Statistical Product and Service Solutions

\section{Declarations}

Ethics approval and consent to participate: This study was approved by the Research Ethics Committee of Division for the Prevention and Control of Chronic Noncommunicable Diseases, China Center for Disease Control and Prevention and the Ethics Committee of Department of Public Health in Fudan University, Shanghai, China. All participants or their legally acceptable representatives provided written informed consent.

Consent for publication: Not applicable.

Availability of data and materials: Datasets used during the current study are available from the corresponding author on reasonable request and with permission of The National Center for Chronic and Noncommunicable Disease Control and Prevention.

Competing interests: The authors declare no conflicts of interest.

Funding: This work was supported by grants from the Scientific Research Project from Shanghai Municipal Committee for Health and Family Planning (20174Y0041 to QX), Scientific Research Starting Foundation from Fudan University (to QX), National Key Research and Development Program of China (2018YFC20020008) and Program for Outstanding Medical Academic Leader, Shanghai, China (2019LJ24). The funders had no role in the design, methods, subject recruitment, data collection, analysis, or preparation of the paper. 
Author contributions: Study conception and design: QX. Data collection: YR, LH, YG, and SS. Acquisition, analysis, or interpretation of data: $X L$ and YR. Statistical analysis: $X L, H C$. Manuscript drafting: $X L$ and QX. Review and comment to manuscript: JG and YS. All authors read and approved the final manuscript.

Acknowledgements: We gratefully thank all participants and the general practitioners for their cooperation.

\section{References}

[1] Hamm NC, Pelletier L, Ellison J, et al. Trends in chronic disease incidence rates from the Canadian Chronic Disease Surveillance System. Health Promot Chronic Dis Prev Can. 2019;39: 216-224.

[2] Health UDo, Services $\mathrm{H}$. The health consequences of smoking: a report of the Surgeon General. US Department of Health and Human Services, Centers for Disease Control and ..., 2004.

[3] Corrao G, Bagnardi V, Zambon A, La Vecchia C. A meta-analysis of alcohol consumption and the risk of 15 diseases. Preventive medicine. 2004;38: 613-619.

[4] Lee I-M, Shiroma EJ, Lobelo F, et al. Effect of physical inactivity on major non-communicable diseases worldwide: an analysis of burden of disease and life expectancy. The lancet. 2012;380: 219-229.

[5] Danaei G, Ding EL, Mozaffarian D, et al. The preventable causes of death in the United States: comparative risk assessment of dietary, lifestyle, and metabolic risk factors. PLoS Med. 2009;6: e1000058.

[6] Scarborough P, Bhatnagar P, Wickramasinghe KK, Allender S, Foster C, Rayner M. The economic burden of ill health due to diet, physical inactivity, smoking, alcohol and obesity in the UK: an update to 2006-07 NHS costs. Journal of public health. 2011;33: 527-535.

[7] Cadilhac DA, Magnus A, Sheppard L, Cumming TB, Pearce DC, Carter R. The societal benefits of reducing six behavioural risk factors: an economic modelling study from Australia. BMC public health. 2011;11: 483.

[8] Lim SS, Vos T, Flaxman AD, et al. A comparative risk assessment of burden of disease and injury attributable to 67 risk factors and risk factor clusters in 21 regions, 1990-2010: a systematic analysis for the Global Burden of Disease Study 2010. The lancet. 2012;380: 2224-2260.

[9] Sattler C, Toro P, Schönknecht P, Schröder J. Cognitive leisure activity, education and socioeconomic status as preventive factors for mild cognitive impairment and Alzheimer's disease. Psychiatry Res. 2012;196: 90-95.

[10] Wilson RS, Scherr PA, Schneider JA, Tang Y, Bennett DA. Relation of cognitive leisure activity to risk of developing Alzheimer disease. Neurology. 2007;69: 1911-1920. 
[11] Verghese J, Lipton RB, Katz MJ, et al. Leisure activities and the risk of dementia in the elderly. $N$ Engl J Med. 2003;348: 2508-2516.

[12] Almeida OP, Yeap BB, Alfonso H, Hankey GJ, Flicker L, Norman PE. Older men who use computers have lower risk of dementia. PLoS One. 2012;7: e44239.

[13] Iwasa H, Yoshida Y, Kai I, Suzuki T, Kim H, Yoshida H. Leisure activities and cognitive function in elderly community-dwelling individuals in Japan: a 5-year prospective cohort study. J Psychosom Res. 2012;72: 159-164.

[14] Kåreholt I, Lennartsson C, Gatz M, Parker MG. Baseline leisure time activity and cognition more than two decades later. Int J Geriatr Psychiatry. 2011;26: 65-74.

[15] Paillard-Borg S, Fratiglioni L, Winblad B, Wang HX. Leisure activities in late life in relation to dementia risk: principal component analysis. Dement Geriatr Cogn Disord. 2009;28: 136-144.

[16] Wang J, Zhou D, Li J, et al. Leisure activity and risk of cognitive impairment: the Chongqing aging study. Neurology. 2006;66: 911-913.

[17] Lindstrom HA, Fritsch T, Petot G, et al. The relationships between television viewing in midlife and the development of Alzheimer's disease in a case-control study. Brain Cogn. 2005;58: 157-165.

[18] Association As. 2019 Alzheimer's disease facts and figures. Alzheimer's \& Dementia. 2019;15: 321-387.

[19] McAdams-DeMarco MA, Daubresse M, Bae S, Gross AL, Carlson MC, Segev DL. Dementia, Alzheimer's Disease, and Mortality after Hemodialysis Initiation. Clin J Am Soc Nephrol. 2018;13: 13391347.

[20] Lee JH, Lee JH, Park SH. Leisure activity participation as predictor of quality of life in Korean urban-dwelling elderly. Occup Ther Int. 2014;21: 124-132.

[21] Khalaila R, Vitman-Schorr A. Internet use, social networks, loneliness, and quality of life among adults aged 50 and older: mediating and moderating effects. Qual Life Res. 2018;27: 479-489.

[22] Murro V, Sodi A, Giacomelli G, et al. Reading Ability and Quality of Life in Stargardt Disease. Eur J Ophthalmol. 2017;27: 740-745.

[23] Kaltenegger K, Kuester S, Altpeter-Ott E, et al. Effects of home reading training on reading and quality of life in AMD-a randomized and controlled study. Graefes Arch Clin Exp Ophthalmol. 2019;257: 1499-1512.

[24] Eifert EK, Hall M, Smith PH, Wideman L. Quality of life as a mediator of leisure activity and perceived health among older women. J Women Aging. 2019;31: 248-268. 
[25] Badia M, Orgaz MB, Verdugo M, Ullán AM, Martínez M. Relationships between leisure participation and quality of life of people with developmental disabilities. J Appl Res Intellect Disabil. 2013;26: 533-545.

[26] Sener A, Terzioğlu RG, Karabulut E. Life satisfaction and leisure activities during men's retirement: a Turkish sample. Aging Ment Health. 2007;11: 30-36.

[27] Lyyra TM, Törmäkangas TM, Read S, Rantanen T, Berg S. Satisfaction with present life predicts survival in octogenarians. J Gerontol B Psychol Sci Soc Sci. 2006;61: P319-326.

[28] Kimm H, Sull JW, Gombojav B, Yi SW, Ohrr H. Life satisfaction and mortality in elderly people: the Kangwha Cohort Study. BMC Public Health. 2012;12: 54.

[29] Collins AL, Glei DA, Goldman N. The role of life satisfaction and depressive symptoms in allcause mortality. Psychol Aging. 2009;24: 696-702.

[30] Li ZH, Zhang XR, Lv YB, et al. Leisure Activities and All-Cause Mortality Among the Chinese Oldest-Old Population: A Prospective Community-Based Cohort Study. J Am Med Dir Assoc. 2020;21: 713719.e712.

[31] Jacobs JM, Hammerman-Rozenberg R, Cohen A, Stessman J. Reading daily predicts reduced mortality among men from a cohort of community-dwelling 70-year-olds. J Gerontol B Psychol Sci Soc Sci. 2008;63: S73-80.

[32] Sattler C, Toro P, Schonknecht P, Schroder J. Cognitive leisure activity, education and socioeconomic status as preventive factors for mild cognitive impairment and Alzheimer's disease. Psychiatry Res. 2012;196: 90-95.

[33] Wilson R, Scherr P, Schneider J, Tang Y, Bennett D. Relation of cognitive leisure activity to risk of developing Alzheimer disease. Neurology. 2007;69: 1911-1920.

[34] Kareholt I, Lennartsson C, Gatz M, Parker MG. Baseline leisure time activity and cognition more than two decades later. Int J Geriatr Psychiatry. 2011;26: 65-74.

[35] Verghese J, Lipton RB, Katz MJ, et al. Leisure activities and the risk of dementia in the elderly. New England Journal of Medicine. 2003;348: 2508-2516.

[36] Li X, Ma C, Zhang J, et al. Prevalence of and potential risk factors for mild cognitive impairment in community-dwelling residents of Beijing. J Am Geriatr Soc. 2013;61: 2111-2119.

[37] Liang X, Chen Z, Dong X, et al. Mental Work Demands and Late-Life Cognitive Impairment: Results From the Shanghai Aging Study. J Aging Health. 2019;31: 883-898.

[38] Sun R, Liu Y. Mortality of the oldest old in China. J Aging Health. 2006;18: 37-55. 
[39] Bassuk SS, Glass TA, Berkman LF. Social disengagement and incident cognitive decline in community-dwelling elderly persons. Annals of internal medicine. 1999;131: 165-173.

[40] Barnes LL, De Leon CM, Wilson RS, Bienias JL, Evans DA. Social resources and cognitive decline in a population of older African Americans and whites. Neurology. 2004;63: 2322-2326.

[41] Newson RS, Kemps EB. General lifestyle activities as a predictor of current cognition and cognitive change in older adults: a cross-sectional and longitudinal examination. The Journals of Gerontology Series B: Psychological Sciences and Social Sciences. 2005;60: P113-P120.

[42] Seeman TE. Social ties and health: The benefits of social integration. Annals of epidemiology. 1996;6: 442-451.

[43] Wang $\mathrm{H}-\mathrm{X}$, Jin $\mathrm{Y}$, Hendrie $\mathrm{HC}$, et al. Late life leisure activities and risk of cognitive decline. Journals of Gerontology Series A: Biomedical Sciences and Medical Sciences. 2013;68: 205-213.

[44] Paffenbarger Jr RS, Hyde R, Wing AL, Hsieh C-c. Physical activity, all-cause mortality, and longevity of college alumni. New England journal of medicine. 1986;314: 605-613.

[45] Kujala UM, Kaprio J, Sarna S, Koskenvuo M. Relationship of leisure-time physical activity and mortality: the Finnish twin cohort. Jama. 1998;279: 440-444.

[46] Paffenbarger Jr RS, Hyde RT, Wing AL, Lee I-M, Jung DL, Kampert JB. The association of changes in physical-activity level and other lifestyle characteristics with mortality among men. New England journal of medicine. 1993;328: 538-545.

[47] Lear SA, Hu W, Rangarajan S, et al. The effect of physical activity on mortality and cardiovascular disease in 130000 people from 17 high-income, middle-income, and low-income countries: the PURE study. The Lancet. 2017;390: 2643-2654.

[48] Best JR, Nagamatsu LS, Liu-Ambrose T. Improvements to executive function during exercise training predict maintenance of physical activity over the following year. Frontiers in human neuroscience. 2014;8: 353.

[49] Daly M, McMinn D, Allan JL. A bidirectional relationship between physical activity and executive function in older adults. Frontiers in human neuroscience. 2015;8: 1044.

[50] Weuve J, Kang JH, Manson JE, Breteler MM, Ware JH, Grodstein F. Physical activity, including walking, and cognitive function in older women. Jama. 2004;292: 1454-1461.

[51] Laurin D, Verreault R, Lindsay J, MacPherson K, Rockwood K. Physical activity and risk of cognitive impairment and dementia in elderly persons. Archives of neurology. 2001;58: 498-504. 
[52] Yaffe K, Barnes D, Nevitt M, Lui L-Y, Covinsky K. A prospective study of physical activity and cognitive decline in elderly women: women who walk. Archives of internal medicine. 2001;161: 17031708.

[53] Etgen T, Sander D, Huntgeburth U, Poppert H, Förstl H, Bickel H. Physical activity and incident cognitive impairment in elderly persons: the INVADE study. Archives of internal medicine. 2010;170: 186193.

[54] Kempermann G, Fabel K, Ehninger D, et al. Why and how physical activity promotes experienceinduced brain plasticity. Frontiers in neuroscience. 2010;4: 189.

[55] Wilson RS, Bennett D, Bienias J, De Leon CM, Morris M, Evans D. Cognitive leisure activity and cognitive decline in a biracial community population. Neurology. 2003;61: 812-816.

[56] Stuss DT, Levine B. Adult clinical neuropsychology: lessons from studies of the frontal lobes. Annu Rev Psychol. 2002;53: 401-433.

[57] Hall PA, Fong GT. Temporal self-regulation theory: A model for individual health behavior. Health Psychology Review. 2007;1: 6-52.

[58] Epplein M, Zheng Y, Zheng W, et al. Quality of life after breast cancer diagnosis and survival. J Clin Oncol. 2011;29: 406-412.

[59] Ratjen I, Schafmayer C, Enderle J, et al. Health-related quality of life in long-term survivors of colorectal cancer and its association with all-cause mortality: a German cohort study. BMC Cancer. 2018;18: 1156.

[60] Sitlinger A, Zafar SY. Health-Related Quality of Life: The Impact on Morbidity and Mortality. Surg Oncol Clin N Am. 2018;27: 675-684.

[61] Kubzansky LD, Huffman JC, Boehm JK, et al. Positive Psychological Well-Being and Cardiovascular Disease: JACC Health Promotion Series. J Am Coll Cardiol. 2018;72: 1382-1396.

[62] Reavell J, Hopkinson M, Clarkesmith D, Lane DA. Effectiveness of Cognitive Behavioral Therapy for Depression and Anxiety in Patients With Cardiovascular Disease: A Systematic Review and MetaAnalysis. Psychosom Med. 2018;80: 742-753.

\section{Figures}




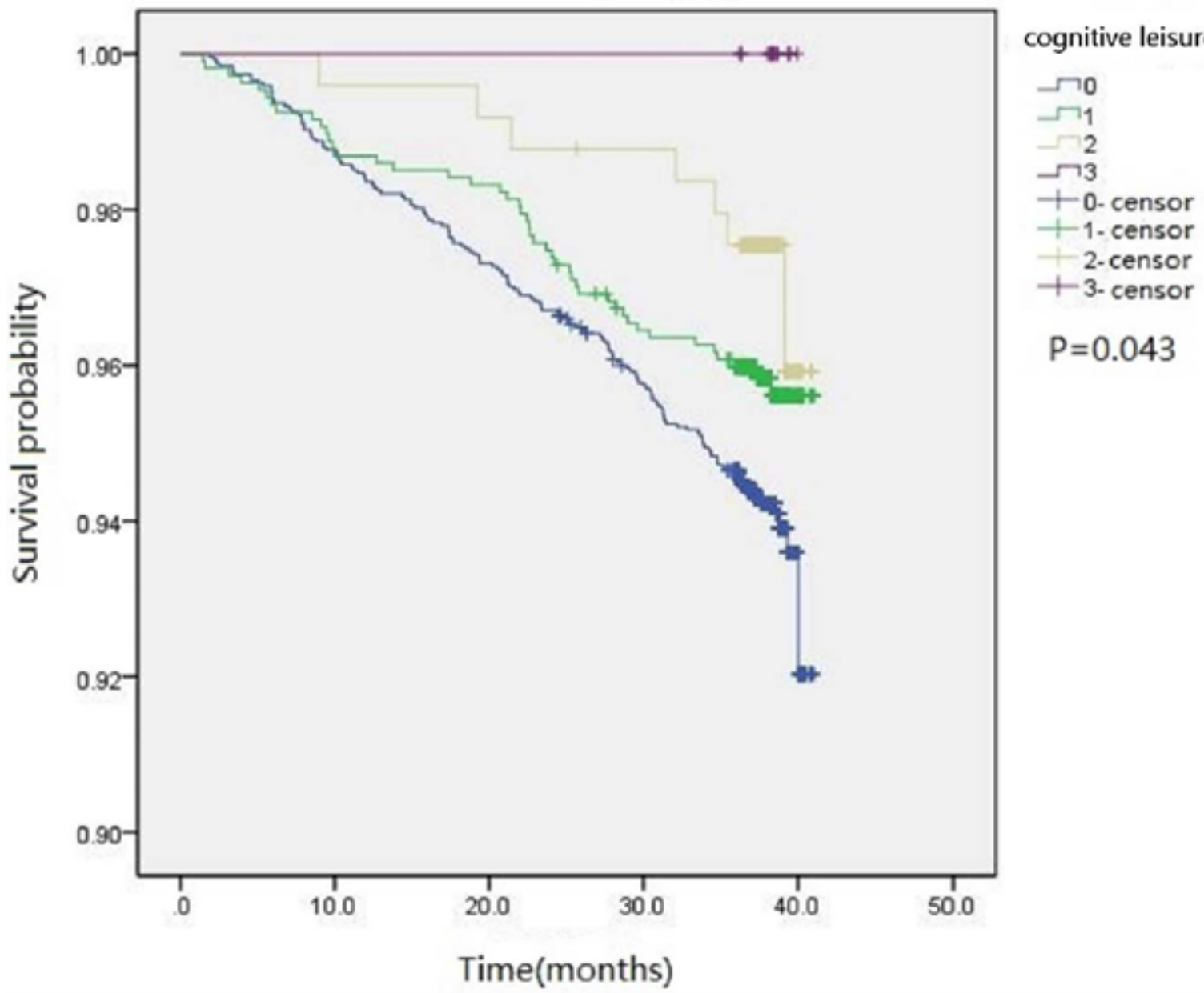

Figure 1

Kaplan-Meier survival curves of cognitive leisure activity index with survival.

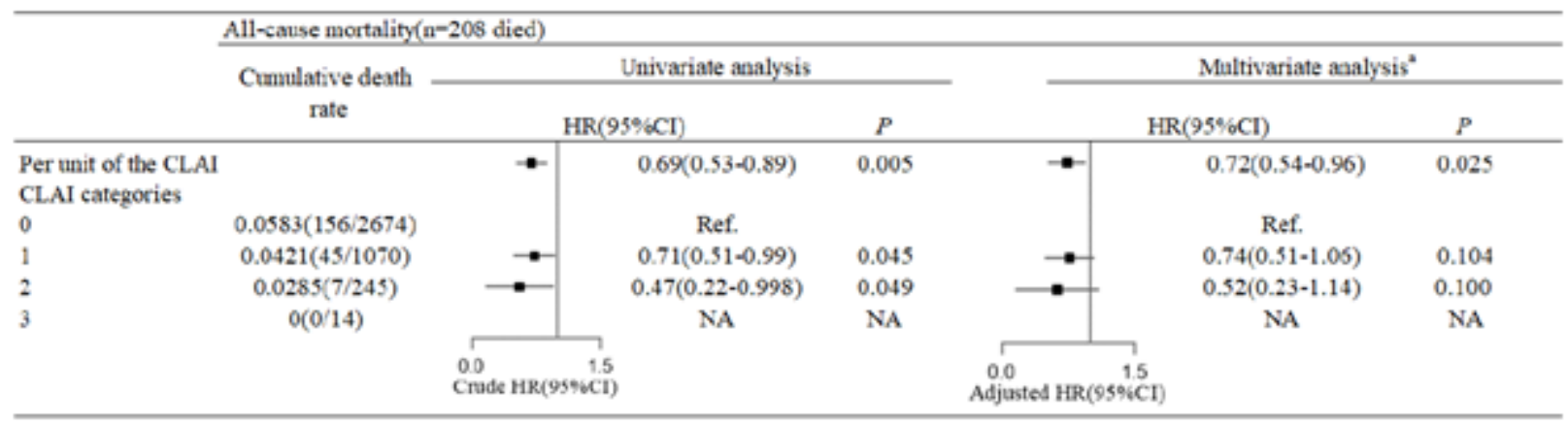

\section{Figure 2}

Crude cumulative death rates and hazard ratios for all-cause mortality by cognitive leisure activity index score among a community-based Chinese elderly samples $(2015-2018, \mathrm{n}=4003)$. $\mathrm{HR}=$ hazard ratio; $\mathrm{Cl}=$ confidence interval. a HR adjusted for age, sex, BMI, smoking status, alcohol use status, marital status, education level, work status, physical activity, cardiovascular disease, cancer. 


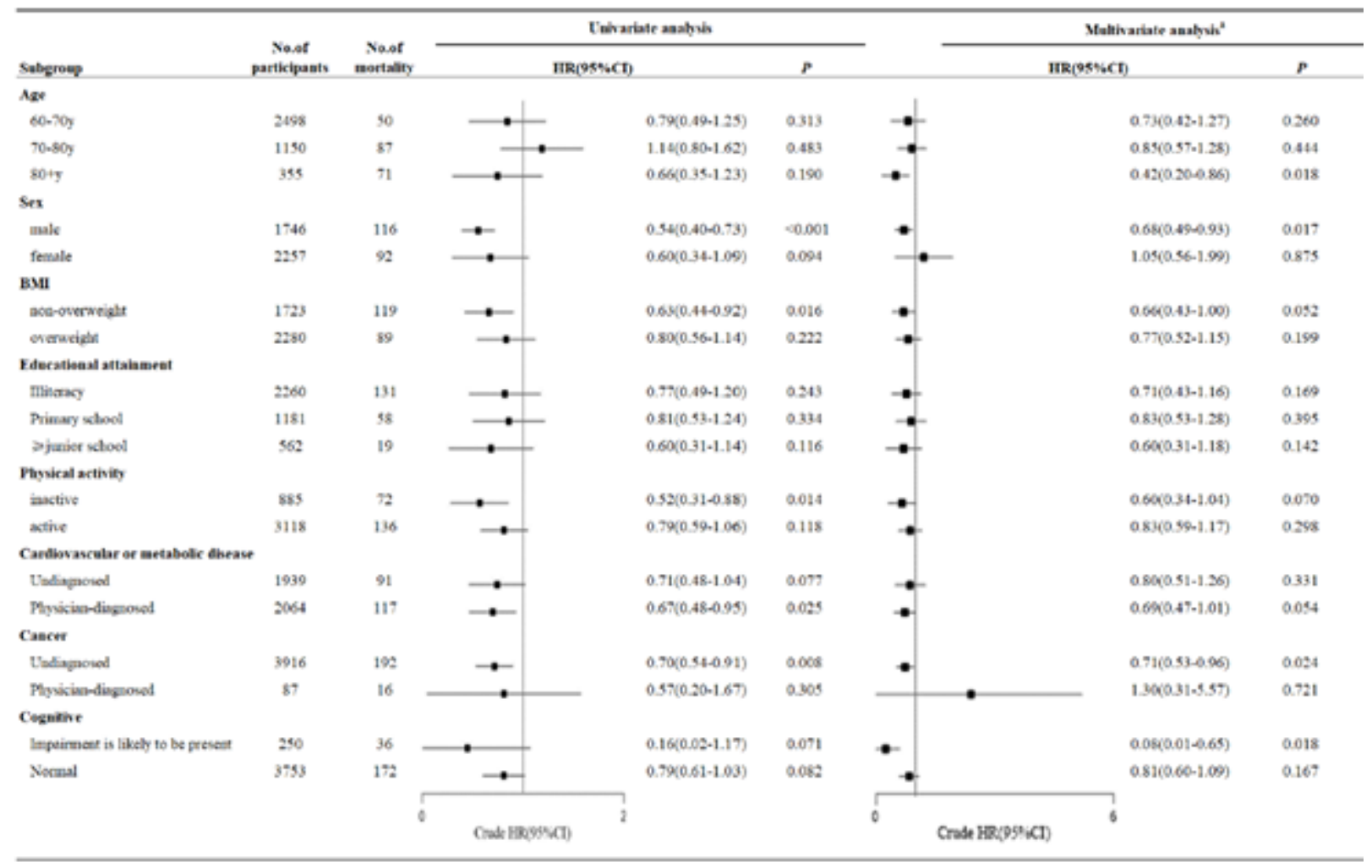

\section{Figure 3}

The association between cognitive leisure activity index and risk of all-cause mortality in stratified subgroup. $\mathrm{HR}$ = hazard ratio; $\mathrm{Cl}$ = confidence interval. a HR adjusted for age, sex, $\mathrm{BMI}$, smoking status, alcohol use status, marital status, education level, work status, physical activity, cardiovascular disease, cancer.

\section{Supplementary Files}

This is a list of supplementary files associated with this preprint. Click to download.

- supplementarymaterial.docx

- Questionnaire.pdf 